Nataša V. Ninčetović*

821.111(73).09-2 Олби Е.

Univerzitet u Prištini

821.111.09-2 Мемет Д.

(sa privremenim sedištem

u Kosovskoj Mitrovici)

Filozofski fakultet

https://doi.org/10.18485/analiff.2019.31.1.2

Originalni naučni rad

Primljen: 15.05.2019

Prihvaćen: 11.08.2019

\title{
SLIKE AMERIKE U DRAMAMA ZOOLOŠKA PRIČA EDVARDA OLBIJA I AMERIČKI BIZON DEJVIDA MEMETA
}

Cilj ovog rada je da uporednom analizom dve značajne moderne američke drame ukaže na slične stavove njihovih autora kada je u pitanju slika posleratne Amerike. Prikazi američkog društva podjednako su sumorni u obe drame, mada se tačke gledišta Dejvida Memeta i Edvarda Olbija donekle razikuju. Olbi naglašava jaz između klasa, dok Memet opisuje život ljudi koji se nalaze na dnu društvene lestvice. Ono što je zajedničko svim likovima u Zoološkoj priči i Američkom bizonu jeste otuđenje, nesposobnost likova da izgrade iskrene međuljudske odnose. Implikacija je da je sistem u kojem živimo nemilosrdan i surov, a svaki pojedinac snosi odgovornost za sopstvenu sudbinu, te se svako ponaosob mora otrgnuti od nametnutog materijalizma i okrenuti sebi i ljudima koji ga okružuju.

Ključne reči: otuđenost, Amerika, kapitalizam, nekompetencija, moral.

Edvard Olbi i Dejvid Memet spadaju u najpoznatije i najznačajnije pisce savremene američke drame. Obojica pišu o propadanju moralnih vrednosti u američkom društvu koje su, prema njihovom mišljenju, posledica konzumerizma i korporativnog kapitalizma. Nakon Drugog svetskog rata usavršavanje tehnologije dovelo je do značajnog povećanja proizvodnje, a uz to su banke nudile kredite koji su ljudima omogućavali da kupuju i troše kao nikada pre. Pored toga, mediji su propagirali stav da je sreća usko povezana sa posedovanjem materijalnih dobara, što je dodatno uticalo na formiranje potrošačkog društva, koje je kupovalo monogo više od onoga što je zadovoljavalo osnovne životne potrebe. Olbi i Memet pišu o usamljenosti pojedinca u takvom društvu, društvu koje ohrabruje ljude da budu sebični i da streme profesionalnom uspehu, ne vodeći računa o

* natasa.nincetovic@.pr.ac.rs 
drugima i ne pokušavajući da ostvare istinski kontakt sa ljudima koji ih okružuju. Njihovi likovi su otuđeni, izolovani, druge ljude doživljavaju kao pretnju. Kako je tvrdio sam Memet, u društvu opterećenom materijalizmom dramaturg oseća moralnu odgovornost da progovori o duhovnosti. Glavni likovi u dramama Zoološka priča (The Zoo Story, 1959) i Američki bizon (American Buffalo, 1975) bar na trenutak ostavljaju po strani materijalno i prolazno i razgovaraju o bitnim pitanjima koja muče svakog pojedinca. Likovi u pomenutim dramama nalaze se u kriznim situacijama. Među njima nema prave komunikacije, nema razumevanja. Džeri se silno trudi da Pitera probudi iz stanja uljuljkanosti u konformizam i na kraju uspeva da dopre do njega, mada po cenu života. Sa druge strane, u odnosu između Dona i Bobija primetan je jaz između onoga što Don priča i onog što radi. Don Bobiju daje savete, usmerava ga kako da se ponaša, ali ga prvom prilikom ostavlja po strani I na nagovor Tiča ne planira da Bobija povede u pljačku. Napetost između trojice sitnih kriminalaca, Dona, Tiča i Bobija, koja kulminira nasiljem prema Bobiju, bar na trenutak utiče na Tiča da počne da misli na svog štićenika, koga uzima u zaštitu i vodi u bolnicu. Don i Piter uspevaju da reše krizu komunikacije i likovi se na kraju drama razumeju, a uspešna komunikacija je verovatno najbolji način da čovek pronađe izlaz iz otuđenosti i izolovanosti.

Memet i Olbi pišu o posleratnoj Americi. SAD su u to vreme definitivno važile za ekonomski najmoćniju zemlju sveta, koja, za razliku od Evrope, nije bila opustošena Drugim svetskim ratom. Međutim, Hladni rat koji je Amerika vodila protiv Sovjetskog Saveza imao je veliki uticaj na kulturni i društveni život američkih građana. U SAD-u su promovisane vrednosti koje su bile dijametralno suprotne „bezbožnom” komunističkom SSSR-u, što je značilo povratak tradicionalnim vrednostima kada su u pitanju porodica, vera i ljudska zajednica. Kako ističu Shams i Pourgiv u eseju Power Struggle in The Zoo Story: A Performance of Subjectivity, veliki uticaj na američko društvo u tom periodu imali su mediji. Mediji su promovisali sliku idealne porodice iz predgrađa, u kojoj je otac bio hranilac porodice, dok je majka vodila računa o kući i deci, dakle, porodice u kojoj su očuvane tradicionalne uloge polova (Shams \& Pourgiv 2013: 2). Mediji su imali za cilj da utiču na što veći procenat stanovništva da pokušaju da dostignu taj ideal. Pored toga, radili su na popularizaciji potrošačkog načina života, plasirajući laž da će ljudi biti srećniji ako budu imali mnogo novca, kuću, auto i sve što se novcem može kupiti. S druge strane, 
u medijima se nije govorilo o problemima unutar samog društva. Naime, u decenijama koje su usledile nakon Drugog svetskog rata produbio se jaz izmedju bogatih i siromašnih. Pripadnici srednje klase živeli su u bezbrižnosti, komforu i neznanju da milioni građana Amerike nemaju osnovne uslove za život. U medijima se malo govorilo o sve glasnijim pokretima koji nisu bili zadovoljni nametanjem konformizma i tradicionalnih vrednosti, kao što su razni pokreti o ljudskim, ženskim i pravima homoseksualaca. Pored toga, nezdravi takmičarski duh koji je uveo korporativni kapitalizam izazvao je propadanje moralnih vrednosti. Svet koji opisuju Olbi i Memet je surov, u njemu se svako mora prilagoditi pravilima sistema. Budući da u tom svetu ništa, pa ni moć, nije stabilno i sigurno, ljudi se stalno bore izmedju sebe, a preživljavaju samo najsposobniji.

Zoo-vrt u Olbijevoj drami simbolizuje Ameriku. Građani Amerike, dakle, žive izolovano, svako u svom kavezu, bez kontakta sa drugima. Pritom je kavez, kako ističu Nabi i Ahmed u eseju Edward Albee's The Zoo Story: Echo/es of Contemporary Subversive Culture, „sačinjen od dominantnih društvenih i kulturnih normi, vrednosti, običaja i verovanja“ (Nabi \& Ahmed 2016: 235). Ljudi poput Pitera (Peter) žive u ovakvim kavezima naivno verujući da je to njihov lični izbor, dok ljudi poput Džerija shvataju sve nedostatke kapitalističkog društva, ustaju protiv života u kavezu i pokušavaju da dopru do drugih ljudi. Kako tvrde Dehgani i Seprehmanesh u eseju Decay of Ethics in David Mamet's American Buffalo, „kapitalizam koristi ideologiju robusnog individualizma ne bi li osigurao eksploataciju i potpunu potčinjenost" (Dehgani \& Sepremanesh 2013: 10) neophodnu za funkcionisanje sistema. $U$ osnovi robusnog individualizma je verovanje da se pojedinac mora takmičiti ne bi li ostvario lične interese, čak iako to šteti drugima. Upravo je robusni individualizam doveo do propadanja moralnih vrednosti koje su nekada bile važne. Korporativni kapitalizam, koji je nametao nezdravi takmičarski duh, učinio je apsolutno nemogućim lični uspeh u sprezi sa očuvanim moralnim vrednostima. U osnovi kasnog kapitalizma je da novcu i uspehu moramo žrtvovati sve, uključujući prijateljstvo, čast i dostojanstvo. Američki san, u čijoj osnovi je verovanje da svi imaju jednake šanse za uspeh, pokazao se kao iluzija za lakoverne. Imajući u vidu različite okolnosti u kojima odrastaju i žive Džeri (Jerry) i Piter (Peter), vidimo da je ljudima poput Džerija veoma teško da uspeju i uživaju iste privilegije kao i pripadnici srednje klase. Takođe, likovi u Memetovom Američkom bizonu su ljudi koji žive na marginama 
društva, ljudi koji se bore da prežive, ljudi poput Džerija i Tiča (Teach), koji nemaju ni svoj dom, već stanuju u iznajmljenim kućama i odsedaju u hotelima. Olbi i Memet biraju ovakve likove jer su mane jednog društva najuočljivije na njegovom dnu.

Tobi Zinman u knjizi The Methuen Drama Guide to Contemporary American Playwrights smatra Dejvida Memeta najistaknutijim dramskim kritičarem američkog društva. Kako tvrdi Zinman, likovi u Memetovim dramama, ,motivisani novcem i pohlepom, iznova i iznova lažu, varaju i manipulišu drugima. Ako to ne daje očekivane rezultate, likovi pribegavaju nasilju. Svako izdaje svakog, a osećaj da su izdani neminovno u njima stvara bes (Zinman 2014: 149). Kritički stav prema američkom društvu naročito je prisutan u Memetovim ranim dramama (a jedna od tih drama upravo je Američki bizon). U zrelijim godinama Memet se više okreće televiziji i filmu i nije vište toliko oštar kada su u pitanju mane američke socijalne scene.

Kao što je u uvodu rečeno, drame Zoološka priča i Američki bizon kao jednu od centralnih tema imaju otuđenost, izolovanost pojedinca. Ljudi su postali hladni i nečovečni. Pritom pojedinci mogu biti vidno usamljeni, kao što je slučaj sa Džerijem. Ljudi poput Pitera, Dona (Don) i Tiča, pak, odaju utisak pojedinaca koji ostvaruju kontakte sa ljudima iz svoje okoline. Međutim, odnosi koje oni ostvaruju samo su privid, maska iza koje se krije samoća i nemogućnost uspostavljanja bliskosti. Kako saznajemo, Piter, i pored toga što ima suprugu i dvoje dece, nedeljom posle ručka sam ide u park da na miru čita knjigu. Porodica je, dakle, samo paravan koji u očima drugih stvara utisak da je Piter zadovoljan i asimilovan pripadnik društva. U Memetovoj drami, pak, likovi su toliko okupirani sobom i svojim ličnim interesima, da ih u većini slučajeva ne zanimaju potrebe i mišljenja drugih ljudi. Pohlepa i lična korist toliko su dominantni da je prijateljstvo na granici izumiranja budući da ljudi samo gledaju na koji način mogu da iskoriste druge. Pošto jezik ne služi za sporazumevanje, već za delovanje, nema razumevanja medju ljudima. Na iskrenost se gleda kao na slabost, iskreni ljudi su otvoreni, samim tim i ranjivi. „Ljudi očajnički žude za kontaktom, za bliskošću, ali je strah od ranjivosti, kako ističe Kristofer Bigzbi (Christopher Bigsby) u svom pregledu moderne američke drame pod nazivom Modern American Drama 1945-2000, veći od straha od samoće." (Bigsby 2004: 217)

Jedna od tema drame Američki bizon je poslovni moral u zapadnom svetu. U poslu, kako vidimo, ne važe ista pravila kao i u životu. U poslu 
je dozvoljeno, čak i poželjno, biti nemoralan i gledati samo ličnu korist. Kapitalizam nas uči da moramo iskoristiti svaku šansu za uspeh, čak iako naš uspeh ide na štetu drugih. Kako je Memet izjavio u intervjuu sa Metjuom Rudanom (Mathew Roudane), ovaj stav je toliko uvrežen u američkom društvu da „onaj ko se ne ponaša u skladu s ovom mantrom ne samo da se smatra luckastim, već u većini slučajeva i nemarnim“ (Roudane, 1984).

Tič Donov zaštitnički stav prema Bobu smatra slabošću, i upravo tu dolazi do konflikta izmedju dvojice prijatelja. Tič, za razliku od Dona, ima potrebu da ga vole i poštuju, ali ne i da ostvari iskreni odnos sa bilo kim. Zato se i podsmeva Donu kad ovaj stane na Bobovu stranu: „Trebaju ti klinci, idi pa ih napravi. Nisam ti ja žena." (Mamet 2001: 73) Možda Don i Bob i jesu "ulična šala", ali se jedino u njihovom odnosu nazire zrno ljudkosti i prijateljstva neophodno za opstanak ljudske zajednice.

$\mathrm{Na}$ kraju drame, nakon što napetost i uzajamno nepoverenje likova kulminiraju jer je Bob priznao da je slagao da je trgovac kovanicama napustio stan, dolazi do fizičkog nasilja. Tič kažnjava Boba, a Don ne radi ništa kako bi ga odvratio. Međutim, deluje da nakon obračuna stvari postaju jasnije. I Bob i Tič mole Dona za oproštaj. Na taj način Don opet postaje glavni, dok su Tič i Bob u podređenim položajima. Dehgani i Seprehmanesh tvrde da su trojica likova na kraju drame poput članova porodice koji su izgladili nesuglasice. Za dvojicu autora ,prodavnica starudija simbolizuje kuću u kojoj se članovi porodice drže zajedno i nalaze utočište od opasnosti koje vrebaju u surovom spoljašnjem svetu" (Dehgani \& Seprehmanesh 2013: 15). Implikacija je da likovi uviđaju da nije problem u drugim ljudima, da je sistem takav da loše utiče na pojedinca, a da se ljudi moraju okrenuti jedni drugima i iskreno nastojati da ostvare bliskost i povezanost sa onima do kojih im je stalo.

Tiča možemo posmatrati kao predstavnika i glasnogovornika kapitalizma i njegove poslovne etike. Pokušavajući da pridobije Donovu naklonost, Tič pokušava da ga ubedi da su mu svi neprijatelji. Uverava ga da Ruti (Ruthie) i Flečer (Fletcher) varaju na kartama, dok je Bob narkoman i samim tim nepouzdan. Tič sa jedne strane želi da Don poveruje da nema prijateljstva, a sa druge strane pokušava da sebe prikaže kao Donovog jedinog pravog prijatelja. Ova Tičova kontradiktorna namera podseća na situaciju na početku drame, kada Don objašnjava Bobu da "U životu nema mnogo prijatelja (Mamet 2001: 10)," dok mu daje smernice za lakše snalaženje u životu. Tič, čije ime u engleskom jeziku znači „učitelj“, pokušava da se nametne kao 
Donov učitelj ili lajf kouč. To što Memet bira nadimak Tič za lik čiji su moral i sposobnosti krajnje sumnjivi svedoči o izopačenim vrednostima i svetu u kojem se krađa naziva poslom, budući da je slobodni poduhvat, kako sam Tič kaže „Sloboda pojedinca da izabere bilo koji jebeni put koji mu se čini pogodnim (Mamet 1976: 60)". O Tičovim izopačenim moralnim vrednostima svedoči scena u kojoj se on sprema da u pljačku ponese revolver. Kako on ističe, u pitanju je puka predstrožnost budući da „sva moguća i nemoguća priprema ništa ne znači ako neki ludak skonta da si upao na njegov posed“" (Mamet 2001: 64). U pitanju je, dakle, poremećeno poimanje stvarnosti budući da je u Tičovim očima čovek koji štiti sopstvenu imovinu ludak. Takođe, Tič sebe poredi sa policajcima koji se naoružani do zuba obračunavaju sa kriminalcima. Tičova percepcija stvarnosti toliko je poremećena da ne uviđa da on, kao sitan lopov, nije na istoj strani sa čuvarima zakona.

Dok se kod Tiča ispod štita kojim se brani od iskrenih i otvorenih odnosa krije strah da će biti povređen, ispod Piterove nezainteresovanosti je nešto drugo. Piter je do te mere vaspitavan i naučen da gleda sebe i svoje interese da on zaista nimalo ne mari za druge i njihove potrebe. Piter je jedan od onih „spavača” koji bi po Olbijevim rečima „radije prespavali život nego što bi ostali budni”. Piter naivno veruje da ima sve što mu je potrebno da bude srećan: kuću, dobar posao, porodicu, dva televizora. On je, prema tome, ostvario svoj san i sad može da uživa, savršeno indiferentan prema tome šta se događa u njegovom okruženju. Ljudima poput Pitera lakše je da misle da svi žive u komforu i blagostanju, baš kao i on i ljudi iz njegove okoline. Zato srednja klasa i snosi delimičnu odgovornost za neljudske uslove u kojima živi ostatak stanovništva, jer zatvara oči pred stvarnošću koja je u neskladu sa njihovim načinom života. Tako i Piter tako umesto realnosti bira iluziju. Iako se pomenuti zoo-vrt nalazi u sklopu Centralnog parka u kojem se odvija radnja drame, Piteru nikada ne pada na pamet da ode do zoovrta, radije se udubljuje u knjigu. Knjiga je ono u šta Piter želi da veruje - to je zaista mnogo lakše nego suočavanje sa surovom stvarnošću.

Piter, dakle, bira lakši put, a to je život u iluziji, u ljušturi u kojoj se skriva od ljudi i sveta. Esej Iluzija i realnost u Zoološkoj priči Edvarda Olbija (Illusion and Reality in Edward Albee's The Zoo Story) ukazuje upravo na dihotomiju stvarnosti i iluzije u Zoološkoj priči. Kako ističu Harehdasht, Hajjari i Shahidzadeh, Piter poput većine pripadnika srednje klase bira da živi u iluziji jer mu to život čini lakšim i podnošljivijim (Harehdasht, Hajjari i Shahidzadeh 2015: 16). Autori pomenutog eseja nagla- 
šavaju da su takvi ljudi po pravilu otuđeni od svoje okoline i sveta uopšte. Džeri, koji za razliku od Pitera žarko želi da sa nekim uspostavi kontakt, shvata da Piter, baš kao i životinje u zoo-vrtu, živi u svom kavezu. Jedini način da dopre do njega je da na silu uđe u kavez (koji simbolizuje klupa u parku) i proba da uveri Džerija da izađe iz ljušture u koju se uvukao (Harehdasht, Hajjari i Shahidzadeh 2015: 17).

Jedan od velikih problema sa kojim se suočavaju likovi u Zoološkoj priči i Američkom bizonu jeste problem identiteta. Naime, u kapitalizmu čovek je sveden na lako zamenljiv šraf, na nebitan deo ogromne mašinerije. U takvom spletu okolnosti čovek gubi svoje ,ja”. Ljudi kao da su izgubili emocije, postali su hladni i nezainteresovani. Džeri, koji je bez posla, porodice, prijatelja i emotivnog partnera, izgubio je svaki kontakt sa ljudima. Ljudi ge vide, primećuju njegovo prisustvo, ali nimalo ne mare za njega. Kap koja je prelila čašu je ravnodušnost koji je čak i pas pokazao prema njemu. Džeri ne vidi smisao u svom životu. Zato i odlučuje da ga okonča, ali to radi na način koji će napokon zaokupiti pažnju ljudi. On bi mogao da izvrši samoubistvo, ali je svestan da će ubistvo imati daleko veći odjek u medijima. Džeri svojom smrću želi da ostvari dva cilja. Prvi je da ljudi napokon obrate pažnju na njega. Drugi cilj je da probudi „spavače” poput Pitera koji svojim nesvesnim potčinjavanjem sistemu omogućavaju njegovo nesmetano funkcionisanje, sa svim njegovim negativnim stranama. Kada su pitanju likovi u Američkom bizonu, njihov glavni problem je, kako tvrdi Bigzbi u svom prikazu američke drame druge polovine XX veka, što je membrana izmedju pojedinca i agresivnog kapitalizma postala propustljiva (Bigsby 2004: 206). Pojedinac, iako veruje da sam odlučuje o svom životu, ustvari je duboko indoktriniran i sve vreme bombardovan raznim ideologijama. U neprestanoj trci za novcem i uspehom čovek je vođen pravilima i normama koje nameće sistem u kojem živi. Ideologije kojima je izložen čovek u kapitalističkom društvu imaju toliko veliki uticaj da poslovna etika utiče ne samo na profesiju kojom se neko bavi, već duboko zadire i u njegov lični život. Tako pojedinac o svemu, a ne samo o poslu, odlučuje u skladu sa pravilima kojima je kroz život naučen, ne pokušavši da sam razmisli i donese odluku.

Postoje izvesne sličnosti između drama Dejvida Memeta i Semjuela Beketa. Tako Abdulah J. Muhamed u eseju Exposing Unethical Nature of David Mamet's American Buffalo poredi Američkog bizona sa dramom Čekajući Godoa. Likovi u ovim dramama čekaju da se pojavi misterio- 
zna ličnost koja treba da im pomogne. Dok Vladimir i Estragon čekaju Godoa, Don i Tič iščekuju Flečera koji treba da ispuni njihov Američki san. Problem likova u Beketovoj drami, dakle, duhovne je prirode, dok su Memetovi likovi okoreli materijalisti. Kako ističe Muhamed, osnovna razlika između ove dve drame je u idealima kojima likovi streme, na šta je definitivno uticao širi drušveni i istorijski kontekst, imajući u vidu da je Američki bizon nastao u doba Hladnog rata (Muhammed 2017: 6). Tajanstvena ličnost koja treba da se pojavi i reši problem se ne pojavljuje u ovim dramama. Implikacija je da je čovek prepušten sebi, da ne možemo očekivati da nam neko drugi da odgovor na bitna pitanja i reši naše probleme. Svaki pojedinac treba da preuzme odgovrnost i potraži svoju sreću.

Priče koje pričaju likovi jako su važne i simbolične. Džeri na taj način pokušava da Piteru skrene pažnju na sebe. Priča o gazdaričinom psu jedinstvena je i Piter će je definitivno zapamtiti, što znači da će i Džeri ostati upamćen. Sa druge strane, ispostavlja se da su Don i Tič, koji se predstavljaju kao ljudi iskusni u svom,,poslu”, hrabri i neustrašivi samo kada razgovaraju. Oni su sigurni samo u priči o krađi novčića sa likom amerčkog bizona. Stvarnost je, pak, puna opasnosti i zamki. Stoga je ovo dvoje ortaka jako sumnjičavo i uzbuđuju se prilikom svakog prolaska policijskog automobila koji patrolira krajem.

Jedna od važnih osobina Olbijevih i Memetovih likova je nesposobnost. Kada su u pitanju Piter i Džeri, njihova glavna inkompetencija je nemogućnost ostvarivanja iskrenog odnosa i bliskosti sa ljudima (i životinjama) iz svoje okoline. Pored toga, Piter, iako direktor izdavačke kuće, pokazuje da mu elokventnost nije jača strana, ne ume da sluša i da saoseća sa drugima. Ako govorimo o Donu i Tiču, oni su primer ljudi koji su hrabri i vešti samo na rečima. Tako se Don predstavlja Bobu kao sposoban preduzetnik, čovek koji zna svoj posao. Medjutim, situacija sa retkim novčićem govori suprotno. Kako saznajemo, Don nije čak ni znao da ima taj novčić, novčić je do tada bio zaturen među drugim starudijama. Prema tome, Don, koji čak ni uz pomoć knjige ne zna koja je vrednost stvari koje prodaje, nije neko ko bi trebalo da uči Boba kako da postane uspešan poslovan čovek. S druge strane, Tič, koji pokušava da se dodvori Donu i sebe predstavi kao iskusnog lopova i provalnika, nema predstavu kako će ući u stan niti kako će obiti sef u slučaju da se ispostavi da se isti nalazi u stanu potencijalne žrtve.

O nesposobnosti Memetovih likova svedoči i njihova jezička nekompetencija. Njihove rečenice su često isprekidane, nedovršene, pune 
psovki i besmislenih reči. Kod njih jezik ne služi za sporazumevanje, već predstavlja akciju. Jezikom likovi pokušavaju da utiču na druge, da ih izmanipulišu i ubede u nešto. Budući da likovi ne slušaju jedni druge, njih ne zanima koje su potrebe i želje njihovih sagovornika. Njihova jezička neveštost ujedno je i društvena neveštost. Kod Olbija takođe nema sporazumevanja medju likovima. Ovde je Džeri inicijator razgovora. On postavlja svom sagovorniku gomilu pitanja. Njegova želja za razgovorom, potreba da ga neko sasluša, toliko je velika da on vrlo često ne može da se strpi i da sačeka Piterov odgovor. Džeri pričanjem pokušava da svom besmislenom životu da značenje. Međutim, Džeriju je izuzetno teško da dopre do Pitera jer je Piter oko sebe podigao zid, zid nezainteresovanosti i nerazumevanja. Džeri je morao da žrtvuje sopstveni život da bi njegova poruka doprla do Pitera. Tako Piter na kraju drame dolazi do spoznaje o surovoj realnosti u kojoj žive milioni odbačenih, ali je tu spoznaju Džeri platio svojim životom.

Kako navodi Kristofer Bigzbi, lekcija kojoj Džeri pokušava da nauči Pitera je da život bez osećanja, bez bola, nije pravi život, već puko životarenje. Sam Džeri je godinama vodio takav život, život bez emocija, ali ga je ravnodušnost koju su svi, pa i jedan pas, pokazali prema njemu, ubedila da život bez emocija ne vredi ništa (Bigsby 2004: 129).

Kao što smo već pomenuli, i Olbijeva i Memetova namera bila je oštra kritika američkog društva, s tim što se razlikuju tačke gledišta. Tako je Olbi prvenstveno zaintrigiran jazom izmeђu klasa, nametanjem konformizma i pobunom protiv njega. Sa druge strane, Memet opisuje kako žive i preživljavaju ljudi na samom dnu društvene lestvice. Džeri, kao tipičan predstavnik anti-establišmenta govori istinu o pravom stanju u Americi, istinu koju većina ljudi ne želi da čuje. Dok on otvoreno iznosi detalje iz svog privatnog života i bez ustručavanja govori o stvarima kojih bi se većina ljudi stidela, Piter ispoljava krajnju nezainteresovanost. Budući da je Džerijeva priča toliko različita od njemu poznatog životnog stila, Piter ne želi da sluša svog sagovornika - on ga ne razume niti želi da ga razume.

Džeri se plaši da će Piter, baš kao i pas, ravnodušno otići od njega. Zato odlučuje da se žrtvuje ne bi li konačno ostvario kontakt sa nekim. Takođe, želi da Pitera nauči onom što je on sam nedavno shvatio. Zato Pitera i naziva „biljkom”, pokušavajući da kod njega izazove reakciju. Džeriju je mrska i sama pomisao na Piterov dosadan život, jer je to život bez izazova. Zato se odlučuje da ne dopusti Piteru da ode. Smrtno ranjen, Džeri je zahvalan Piteru što nije otišao i što mu je omogućio da konačno 
sa nekim uspostavi kontakt: „Hvala, Pitere. Stvarno, zbilja hvala. ... O, Pitere, stvarno sam se u jednom trenutku uplašio da ću uspeti da te oteram. Ne znaš koliko sam se plašio da ćeš otići i ostaviti me.” (Olbi 1964: 15)

Klupa na kojoj Piter sedi na početku drame i koju mu na kraju oduzima Džeri simbolizuje Piterovu poziciju u životu. Piteru se njegova pozicija na klupi, baš kao i u životu, čini sigurnom samo zato što je do sada niko nije doveo u pitanje. Nakon svađe koja se završava probadanjem Džerija, Piter je primoran da napusti klupu. On, koji je do tada bio okoreli materijalista, ostao je bez jednog dela svoje imovine: „Nećeš više dolaziti ovamo, oduzeta ti je imovina. Izgubio si svoju klupu, ali si odbranio čast" (Olbi 1964: 15). Ovaj događaj treba da natera Pitera da shvati da ne treba da gradi sreću na materijalnim stvarima, već na bliskosti i povezivanju sa ljudima.

Džeri pominje jedan zanimljiv detalj iz svog života, poverava Piteru da je u tinejdžerskim godinama imao homoseksualna iskustva. U vreme kad je ova drama nastala Amerika je bila (ili je tako bar trebalo da deluje) konzervativnija nego ikad. Homoseksualci su bili diskrimisani do te mere da ih je Komitet za sprečavanje komunističkih aktivnosti na čelu sa Džozefom Mekartijem izjednačavao sa komunistima. Kako navodi Mary Jo Bona u eseju pod nazivom Gay and Lesbian Writing in Post-World War II America, komitet je tvrdio da su „homoseksualci podložni ucenama te da stoga moraju biti prognani iz društva ili kažnjeni zatvorskom kaznom" (Bona 2004: 210).Da je homoseksualno opredeljenje bilo vrlo nepoželjno svedoči jedan primer u drami. Kada Džeri pokuša da oduzme Piteru klupu i počne da ga udara, Piter se osvrće oko sebe i pokušava da pozove policiju. Međutim, problem je u tome što su svi policajci „u zapadnom delu parka. Jure toplu braću iz žbunova. Gotovo da je to sve što oni rade. To je njihova jedina funkcija" (Olbi 1964: 13).

Kako ističe Schuchi Agrawal u eseju Gender, Sexuality and Power Relations in Edward Albee's The Zoo Story, Džerijeva seksualna orijentacija je jedan vid bunta protiv normi i konvencija koji su vladali u posleratnoj Americi (Agrawal 2017:11). U vreme kad su homoseksualci bili diskriminisani i kada je vlast nastojala da se očuvaju tradicionalne uloge polova Džeri otvoreno govori o tome da više voli muškarce. On na taj način želi da skrene pažnju Pitera na sebe, ali istovremeno simbolizuje sve one manjinske i ugrožene grupe koje su 50 -ih I 60-ih počele da protestuju i da se bore za ostvarivanje svojih prava. 
U ove dve drame jedini lik o kojem imamo širu sliku svakako je Džeri, dok o ostalim likovima znamo vrlo malo. Autori ne pišu o njihovoj prošlosti, naročito Memet. Mi ne znamo da li Tič, Don i Bob imaju porodice, ne znamo gde žive (osim što se pominje da je Tič smešten u hotelu). Ne znamo ni od čega živi Tič. Jedini lik koji ima kakav-takav posao je Don, vlasnik starinarnice. Stiče se utisak da su oni, za razliku od Pitera koji bar naizgled ima sređen i normalan život, prekinuli sve veze sa spoljnim svetom i da imaju samo jedni druge. Za razliku od Dona, koji veruje u mogućnost istinskog i iskrenog povezivanja sa ljudima, Tič je uveren da tako nešto ne postoji. Ljudi poput njega, koji ne poseduju otvorenost neophodnu za ostvarivanje bliskosti, mogu samo da žale nad nesaznatljivošću drugog i sveta koji ih okružuje.

Ne treba da nas zavara to što ova drama u svom središtu ima tri sitna lopova, od kojih je jedan narkoman. Ona se odnosi na sve slojeve američkog društva, s tim što se loše strane nacionalnog karaktera najuočljivije na samom dnu društvene lestvice. Memet je ovom dramom pokazao šta je to trulo u američkom društvu, koje su to loše strane Američkog sna i zašto su laž i prevara bile ključne odlike perioda u kojem je ova drama nastala.

Složićemo se sa Hanom Knap (Hannah Knapp) da nam Američki bizon daje uvid u to koliko su daleko ljudi u stanju da idu da bi došli do nečega (Knapp 2002: 30). U jednom svom intervjuu Memet otvoreno kaže da u ,potrošačkom društvu nema toga što ne bismo uradili kada bi nam neko rekao, ili bismo intuitivno pomislili, da ćemo tako zaraditi ili da će nas to učiniti srećnim kroz konzumerizam" (Covington, 1997). Kako saznajemo iz drame, posao i prijateljstvo ne idu zajedno u kapitalističkom društvu. Likovi pokušavaju da balansiraju izmedju ,posla” i prijateljstva, ali na kraju uvek daju prednost svojim ,poslovnim” interesima. Ispostavlja se da su Donove reči upućene Bobu na početku drame da „U ovom životu nemaš prijatelje“ (Mamet 1976: 6), apsolutno tačne. Budući da je, kako ističe Vesna Bratić u svojoj doktorskoj disertaciji Slike Amerike u dramama Sema Šeparda i Dejvida Memeta, otudjenost u postmodenom dobu koje Memet opisuje na vrhuncu i da ljudi ne poseduju otvorenost neophodnu za ostvarivanje bliskosti, „ljudima poput Tiča ostaje samo da žale nad nesaznatljivošću drugog i sveta koji nas okružuje" (Bratić 2011: 65). Donova veličina leži u tome što nakon fizičkih okršaja u radnji dolazi do spoznaje da je izdao Boba, zbog čega je moralniji od Tiča i poseduje zrno čovečnosti. 
Simbolika ima značajnu ulogu u Američkom bizonu i Zoološkoj priči. U Zoološkoj priči glavni simbol je upravo zoo-vrt. Način na koji životinje žive u zo vrtu, kavezima odvojene od ljudi i jedne od drugih, simbolizuje život čoveka u postmodernom dobu. Ljudi su usamljeni, otuđeni, bez dodira sa svojom okolinom. Ograničenja koja društvo nameće, poput normi, pravila, klasa, sputavaju čoveka i predstavljaju rešetke kaveza u kojem se nalazi savremeni čovek.

Kada govorimo o Američkom bizonu u simboličkom smislu, valja pomenuti starinarnicu u kojoj se odvija dramska radnja. Kako saznajemo, većina stvari koje Don prodaje predstavlja ono što je preostalo od izložbe povodom obeležavanja stogodišnjeg napretka („Century of Progress Exposition”), a koja je održana u Čikagu 1931. godine. Kako tvrdi Bigzbi, Donijeva starinarnica svedoči o, ,jukstapoziciji materijalnog napretka s jedne i duhovnog nazadovanja sa druge strane" (Bigsby 2004: 212). Najbolji primer moralne dekadencije nalazimo pri kraju drame, kada Bobovo priznanje da je izmislio da je trgovac kovanicama sa koferom napustio stan izazove erupciju nasilja. U tom trenutku sve izrečeno o moralu i prijateljstvu pada u vodu. Kako navodi Metju Rudan u eseju pod nazivom Betrayal and Friendship in American Buffalo, ,fizičko nasilje kojem pribegavaju likovi svedoči o ljudima koji se ponašaju poput primitivaca na rubu civilizacije“" (Roudane 2004: 70).

I sam naslov drame vrlo je simboličan. Američki bizon je životinja koja je dovedena na granicu izumiranja prilikom osvajanja američkog zapada. Bizon simbolizuje ljudske vrednosti koje su bile sastavni deo Američkog sna u njegovom originalnom značenju, vrednosti koje su, kao i bizon, praktično izumrle. Ubijanje bizona je pravdano poslom, baš kao i pljačkanje Indijanaca. Imajući to u vidu, ne čudi što Don i Tič na kradju gledaju kao na poslovni poduhvat kojim će se osvetiti čoveku koji ih je „,nasamario" i tako stekao trenutnu prednost.

\section{Zaključak}

Kako tvrdi Bigzbi, Memetova namera kroz pisanje drama je da sruši mit o Americi (Bigsby 2004: 200). SAD, prema verovanju Memeta, zapravo ne postoji, bar ne u obliku u kojem se predstavlja širokim masama. Kao ilustraciju njegovog stava pomenućemo tvrdnju izrečenu u drami Vodena pumpa (The Water Engine, 1978) da je Amerika ustvari ,veštački skup ljudi različitih jezika, običaja i tradicija čiji je jedini zajednički imenilac to što ih 
je istorija osudila da žive zajedno ne znajući i ne voleći jedni druge (Mamet 1978: 64)." Upravo je društvena raznolikost, koja je vrlo izražena u Americi, jedan od faktora koji su doveli do otuđenosti i izolovanosti pojedinca. Usamljenost je naročito izražena u velikim gradovima gde se živi brzo i gde svako ,gleda svoja posla”, imajući u vidu da se interesovanje za druge često tumači pogrešno. Upravo je u velikim gradovima društvena heterogenost najveća; ovde su sabrani ljudi najrazličitijih nacionalnosti, religija i kultura. Stoga ne čudi što su Memet i Olbi radnje svojih drama smestili u kosmopolitske gradove kao što su Njujork i Čikago. Na taj način dobijamo potpunu sliku kakav je zapravo život u ,obećanoj zemlji”, koliko se razlikuje od onog što nam plasiraju mediji. Dvojica autora naročitu pažnju posvećuju gubitnicima, ljudima koji nisu uspeli da ostvare svoj Američki san. Poruka je jasna: da, mnogi se bore da ostvare svoj san, ali će uspeti samo nekolicina. Ispod njih ostaje gomila "luzera" koji se i dalje nalaze na marginama društva.

Zoološka priča i Američki bizon nam daju vrlo opipljive reprezentacije života u posleratnoj Americi. U periodu u kojem su nastale ove drame SAD su se izdvojile kao vojno i ekonomski najmoćnija država na svetu. Ovaj ekonomski i vojni razvoj doneo je sa sobom brojne promene u društvu, promene sa kojima nisu svi mogli održati korak. Nekada zemlja koja je obećavala „bolji, srećniji i bogatiji život za sve američke gradjane bez obzira na rang i status" (Adams 1931: 214), ali uz očuvanje morala i dostojanstva, sada je pod plaštom korporativnog kapitalizma propagirala robusni individualizam i nezdravi takmičarski duh. Umesto slobode i blagostanja, ljudima je nametnut konzumerizam i konformizam. U takvim uslovima pripadnici srednje glase su uglavnom, baš kao i Piter, prigrlili materijalnu sigurnost i zadovoljili se rutinskim životom, životom bez izazova i uzbuђenja. Oni nisu imali sluha za probleme onih brojnijih, prema kojima život nije bio baš naklonjen. Ljudi poput Džerija shvataju koji su to gorući problemi u postmodernom svetu. Usamljenost, otuđenost pojedinca dostigla je neslućene razmere. Ljudi mogu biti vidno usamljeni, poput Džerija. Medjutim, ni oni članovi društva koji naizgled održavaju bliske odnose sa ljudima iz svoje okoline nisu u mnogo boljem položaju. Kod Pitera je porodica samo paravan koji mu pomaжe da u očima drugih izgleda kao srećan $\mathrm{i}$ ispunjen čovek. Memet, pak, opisuje drugi vid usamljenosti. Don i Tič, naizgled prijatelji, zapravo uopšte ne slušaju jedan drugoga, obojica samo gledaju kako da na najbolji način ostvare lične interese. Oni su prototip ljudi u postmodernom dobu, ljudi koje društvo uči da moraju da gledaju samo 
sebe i da u poslu (i životu) nema prijatelja. Jedini moralni lik je narkoman Bobi. Bob je jedini lik koji se ne uklapa u generalni duh vremena u kojem je drama nastala. Njegova privrženost i dobre namere prema Donu jedina su svetla tačka u okruženju u kojem se ljudi ponašaju poput ptica grabljivica.

\section{LITERATURA}

Adams, J. (1931). The Epic of America. Boston: Little, Brown and Co.

Agrawal, S. (2017). Gender, Sexuality and Power Relations in Edward Albee's The Zoo Story. In: Veda's Journal of Enlish Language and Literature, Vol. 4, Issue 2 (pp. 9-12). Vijayawada: JOELL.

Bigsby, C. W. E. (2004). Modern American Drama 1945- 2000. Cambridge: Cambridge UP.

Bona, M. J. (2004). Gay and Lesbian Writing in Post-World War II America. In: Hendin, J, A Concise Companion to Postwar American Literature and Culture (pp. 210-237). Oxford: Blackwell Publishing.

Bratić, V. (2011). Slike Amerike u dramama Sema Šeparda i Dejvida Memeta (neobjavljena doktorska disertacija). Filološki fakultet, Beograd.

Covington, Richard (1997). "The Salon Interview: David Mamet”. Salon, 24, 10. [on-line]. Dostupno preko: http://www.upstartfilmcollective.com/portfolios/jcharnick/mamet-museum/salon-interview.html [5.10.2018.]

Dehgani, E. \& Seperhmanesh, M. (2013). Decay of Ethics in David Mamet's American Buffalo. In: J.I. Liontas, Y. Golebiowski \& J.Mukundan, International Journal of Applied Linguistics \& English Literature, Vol. 2, No. 5 (pp. 10-19). Footscray: AIAC.

Harehdasht, H.A., Hajjari, L. \& Shahidzadeh, Z. S. (2015). Illusion and Reality in Edward Albee's The Zoo Story. U: Studies in Literature and Language, Vol. 10, No. 6 (pp.15-21). Brossard: CAOOC.

Knapp, H. (2002). The American Dream in American Buffalo. U: Brodersen, Werner and Knapp (eds.), American Buffalo: Words on Plays (pp. 30-32). American Conservatory Theater.

Lahr, J. (2011). David Mamet, The Art of Theater No. 11. U: The Paris Review. Theparisreview.org, 142, 1997. [on-line]. Dostupno preko: https://www. theparisreview.org/interviews/1280/david-mamet-the-art-of-theater-no11-david-mamet [18.11.2018]

Mamet, D. (2001). Američki bizon. U: Borivoj Gerzić (prev.), Izbor iz savremene anglo-američke drame. Beograd: ISTAR.

Mamet, D. (1978). The Water Engine. New York: Grove Press. 
Muhammed, A. J. (2017). Exposing Unethical Nature of David Mamet's American Buffalo. U: Journal of Babylon Center for Humanities Studies, Vol. 7, Issue 2 (pp.1-20). Hillah: University of Babylon.

Nabi, N. \& Ahmed, F. (2016). Edward Albee's The Zoo Story: Echo/es of Contemporary Subversive Culture. U: A. Bodorno (ed.), Advances in Language and Literary Studies, Vol. 7, No. 1 (pp. 235-241). Footscray: AIAC.

Olbi, E. (1964). Zoološka priča, prev. Slobodan Selenić. U: Avangardna dra$m a$. Beograd: SKZ. Vdocumnets. [on-line]. Dostpno preko: https://vdocuments.site/zooloska-prica-edvard-olbi.html [15.3. 2018.]

Roudane, M. (2004). Betrayal and Friendship in American Buffalo. U: C. W. E. Bigsby (ed.), The Cambridge Companion to David Mamet (pp. 57-73). Cambridge: Cambridge UP.

Shams, P. \& Pourgiv, F. (2013). Power Struggle in The Zoo Story: A Performance of Subjectivity. U: Fe Dergi 5, no. 1 (pp. 1-11). Ankara: Ankara Üniversitesi KASAUM.

Zinman, T. (2014). David Mamet. U: M. Middeke, P.P. Schnierer, C. Innes etc. (eds.), The Methuen Drama Guide to Contemporarz American Playwrights. London: Bloomsbury Publishing Plc.

\title{
Nataša V. Ninčetović
}

\section{IMAGES OF AMERICA IN THE PLAYS BY EDWARD ALBEE (THE ZOO STORY) AND DAVID MAMET (AMERICAN BUFFALO)}

\begin{abstract}
Summary
The aim of this paper is to point out to similar attitudes of Edward Albee and David Mamet when it comes to the image of post-war America by means of comparative analysis of two significant modern plays. Their representations of American society are equally gloomy, though their points of view are somewhat different. Albee emphasizes the chasm between the classes, while Mamet depicts the life of people who are at the bottom of the social ladder. What is common to all the characters in The Zoo Story and American Buffalo is alienation, incompetence of characters to create genuine interpersonal relationships. Though the characters come to the realization that something is wrong with their lives, the authors do not provide us with the final solution of the crisis. The moral is that each individual bears responsibility for his destiny, hence every single one has to renounce materialism and turn to himself and the people around him.
\end{abstract}

Key words: alienation, America, capitalism, incompetence, moral. 